\title{
ESTADO DO CONHECIMENTO SOBRE FORMAÇÃO DE PROFESSORES DE INGLÊS PARA CRIANÇAS: O QUE REVELAM OS ESTUDOS PUBLICADOS NOS ÚLTIMOS DEZ ANOS?
}

\begin{abstract}
State of knowledge about the education of English teachers for children: what do the studies published in the last ten years reveal?
\end{abstract}

\author{
Ana Paula LIMA \\ Universidade Estadual Paulista "Júlio de Mesquita Filho" \\ anapl.letras@yahoo.com.br \\ orcid.org/0000-0003-0293-9161 \\ Cláudia Jotto KAWACHI-FURLAN \\ Universidade Federal do Espírito Santo \\ claudia.furlan@ufes.br \\ https://orcid.org/0000-0003-4699-6774
}

\begin{abstract}
RESUMO: O objetivo deste artigo é discutir os dados de um estado do conhecimento acerca da formação de professores de língua inglesa para crianças (LIC). O estudo foi desenvolvido por meio da consulta ao tema em 63 revistas brasileiras on-line, no estrato A do Qualis Periódicos (2013-2016), no período de 2010 a 2020. Foram encontrados apenas três estudos, cujos focos envolvem formação inicial, formação continuada e formação crítica de professores de LIC. As autoras desses trabalhos enfatizam a necessidade de formação específica nos cursos de Letras e também salientam a importância da formação continuada, que é compreendida como integrante do processo de desenvolvimento profissional e privilegia momentos de reflexão e partilha de experiência. As pesquisadoras defendem, ainda, a formação crítica e reflexiva dos docentes, para que possam fazer escolhas conscientes para os contextos nos quais atuam. Considerando que as discussões apresentadas nesses trabalhos publicados há dez anos são ainda atuais, ressaltamos a urgência de regulamentação da oferta do ensino de línguas estrangeiras na Educação Infantil e anos iniciais do Ensino Fundamental e a relevância de estudos na área de formação de professores de LIC, a fim de contribuir com a formação crítica e planejada desses profissionais. PALAVRAS-CHAVE: Formação de professores; Ensino de inglês para crianças; Estado do conhecimento
\end{abstract}




\begin{abstract}
The aim of this article is to discuss findings of a state of knowledge research about the education of English teachers for children. The research was developed by searching for the theme in 63 Brazilian online journals, which were classified in the top tiers of Qualis Periódicos (2013-2016), from 2010 to 2020. Only three studies were found and they focus on English teachers pre-service, in-service and critical teacher education of English teachers for children. The authors of these studies emphasize the need for specific formation in Languages and Literature programs. They also support the importance of in-service education, understood as part of the process of professional development, that favors moments of reflection and experience sharing. The researchers defend critical and reflexive teacher education, so that teachers can make conscious choices for their contexts. Considering that the discussions in these studies published about ten years ago are still current, we emphasize the urgency of regulating the teaching of foreign languages for children in early childhood education and in the first years of elementary school, as well as the relevance of studies about the education of English teachers for children, to contribute to the critical and planned education of these professionals. KEYWORDS: Teacher education; Teaching English to young learners; State of knowledge.
\end{abstract}

\title{
INTRODUÇÃO
}

Neste artigo, discutimos os dados de um levantamento da literatura acadêmica acerca da formação de professores de língua inglesa para crianças (LIC) em revistas ${ }^{1}$ brasileiras on-line, qualificadas no estrato A do Qualis Periódicos (2013-2016), no período de 2010 a 2020.

A oferta da disciplina de língua inglesa na Educação Infantil e nos anos iniciais do Ensino Fundamental é facultativa no Brasil (BRASIL, 1996). No entanto, podemos observar há a oferta dessa disciplina em vários locais, podendo ser considerada uma realidade em nosso país, conforme retratado no mapeamento realizado por Tanaca (2017). É válido ponderar o ensino de inglês para crianças nos anos iniciais da Educação Básica pública e privada, em geral, tem sido impulsionada por questões administrativoburocráticas (LIMA, 2019; SANTOS, 2005; 2009) e mercadológicas (ASSIS, 2018; CHAGURI; TONELLI, 2019; FORTES, 2014; 2017; MALTA, 2019).

Assim, os motivos para a oferta de LIC, a falta de regulamentação desse ensino e de diretrizes oficiais nacionais que orientem o fazer docente e a formação de

\footnotetext{
${ }^{1}$ Neste trabalho, os termos revistas e periódicos estão sendo usados como sinônimos. Revista X, v. 16, n. 3, p. 643-663, 2021.
} 
profissionais para atuarem nesse contexto (ROCHA, 2006, 2007, dentre outros), bem como a complexidade de se ensinar uma língua estrangeira para crianças, faz da área um campo fértil para investigações.

De acordo com levantamento realizado por Tonelli e Pádua (2017), as dissertações e teses publicadas no período de 1987 a 2017, sobre ensino, aprendizagem e formação de professores de língua estrangeira para crianças, abordam diferentes temáticas, como o ensino bilíngue, a formação de professores, o ensino por meio de gêneros e o material didático. Tais documentos estão disponibilizados no Banco de Teses e Dissertações da Coordenação de Aperfeiçoamento de Pessoal de Nível Superior (CAPES) ${ }^{2}$, bem como em sites de universidades públicas brasileiras e da Pontifícia Universidade Católica de São Paulo.

No que se refere especificamente aos trabalhos sobre formação de professores, foco de interesse deste trabalho, as autoras identificam que, em geral, se tratam da prática docente do próprio pesquisador, que identificam os conhecimentos necessários para ensinar uma língua estrangeira para crianças, analisam a maneira de ser do professor que atua nesse contexto, as representações e identidades dos sujeitos envolvidos no processo, e propõem sugestões para a formação docente (TONELLI; PÁDUA, 2017).

Lima e Neto (prelo) fizeram um levantamento específico das dissertações e teses que focalizam a formação de professores de LIC. Nesse levantamento, os autores consideraram não apenas os trabalhos disponíveis no Catálogo de Teses e Dissertações da CAPES, mas também na Biblioteca Digital Brasileira de Teses e Dissertações ${ }^{3}$, no período de 1987 a 2020. Além disso, foram incluídas no mapeamento as pesquisas desenvolvidas em universidades particulares, que não compunham o corpus do estudo realizado por Tonelli e Pádua (2017). Em síntese, tais pesquisas visam compreender como ocorre a formação inicial dos professores de inglês dos anos iniciais da educação básica e quais são suas experiências profissionais; identificar o perfil do professor de LIC, analisar suas concepções de ensino-aprendizagem-avaliação, assim como investigar como ocorre, de fato, esse processo na prática, além de tratarem da formação continuada de professores para esse contexto.

\footnotetext{
${ }^{2}$ O Banco de Teses e Dissertações da CAPES, atualmente denominado Catálogo de Teses e Dissertações da CAPES, disponibiliza informações acerca das dissertações de mestrado e teses de doutorado defendidas em programas de pós-graduação do Brasil desde o ano de 1987. Os programas de pós-graduação fornecem os dados à CAPES e se responsabilizam pela veracidade dos mesmos.

${ }^{3}$ Lançada oficialmente em 2002, a Biblioteca Digital Brasileira de Teses e Dissertações reúne, em um único portal de busca, textos completos das dissertações e teses defendidas nas instituições brasileiras de ensino e pesquisa.
} 
Entendemos que estudos dessa natureza são importantes no sentido de examinar o conhecimento já construído na área, identificar os temas investigados e aqueles que ainda carecem da atenção dos pesquisadores. Sendo assim, com o intuito de complementar os mapeamentos já realizados anteriormente e, principalmente, de compreender como a formação de professores de LIC tem sido discutida em pesquisas acadêmicas, neste artigo, apresentamos e discutimos os dados de um levantamento dos artigos publicados em periódicos on-line brasileiros qualificados no estrato A do Qualis Periódicos ${ }^{4}$ (20132016) a partir do ano de 2010, quando é publicada a resolução $n^{\circ} 7$, primeiro documento oficial nacional que define o profissional licenciado em Letras como responsável pelas aulas de língua estrangeira nos anos iniciais do Ensino Fundamental, até o ano de 2020.

Optamos por selecionar artigos publicados em revistas on-line tendo em vista que esses trabalhos não compunham os levantamentos anteriormente realizados. Além disso, entendemos que se tratam de estudos de fácil acesso e com grande visibilidade acadêmica, principalmente os publicados em periódicos classificados como A1 e A2, nos quais esperamos encontrar trabalhos de referência nacional e internacional.

Além desta introdução, este artigo contém o item "desenvolvimento da pesquisa", no qual detalhamos como foi feita a busca por estudos sobre formação de professores de inglês para crianças e quais trabalhos foram encontrados. Após uma breve contextualização desses trabalhos, passamos a discutir, nos itens subsequentes, os tópicos abordados pelas pesquisas que compõem a nossa amostra, a saber: formação inicial, formação continuada e formação crítica e planejada de professores de LIC. Nessas três seções, retomamos as reflexões das pesquisas analisadas, visando expandir as discussões sobre essas questões na contemporaneidade.

\section{DESENVOLVIMENTO DA PESQUISA}

Neste texto, apresentamos e discutimos os dados de um levantamento dos artigos publicados em periódicos on-line brasileiros qualificados no estrato A do Qualis Periódicos (2013-2016) no período de 2010 a 2020. A pesquisa caracteriza-se, portanto, como um estudo do tipo estado do conhecimento.

Romanoswki e Ens (2006, p. 39) explicam que, ao contrário de pesquisas denominadas estado da arte, que "abrangem toda uma área do conhecimento, nos diferentes aspectos que geraram produções", como as dissertações e teses, apresentações

\footnotetext{
${ }^{4} \mathrm{O}$ Qualis é um sistema brasileiro de avaliação de periódicos, mantido pela CAPES, que relaciona e classifica as revistas dos programas de pós-graduação do tipo "stricto sensu" tanto no que se refere à circulação quanto à qualidade, por área de avaliação.
}

Revista X, v. 16, n. 3, p. 643-663, 2021. 
em congressos da área e artigos publicados em periódicos, os estudos de estado do conhecimento abordam apenas um setor das publicações acerca do tema. Sendo assim, reconhecemos as limitações deste estudo no que se refere à sua abrangência e a importância para a área de formação de professores de LIC de artigos publicados em periódicos que não compõem nossa amostra.

Iniciamos a pesquisa identificando as revistas qualificadas no estrato A do Qualis Periódicos na área de linguística e literatura, no triênio 2013-2016, última avaliação disponibilizada pelo sistema. Na busca, encontramos 245 periódicos, sendo 88 qualificados como A1 e 157 qualificados como A2.

Como nosso foco eram os periódicos brasileiros, verificamos cada uma das revistas e selecionamos apenas as publicadas por programas de pós-graduação de nosso país. Após essa seleção, passaram a compor nossa amostra 22 periódicos A1 e 41 periódicos A2, totalizando 63 revistas.

O passo seguinte da pesquisa consistiu em destacar, em cada uma das revistas, trabalhos voltados para a formação de professores de LIC publicados a partir do ano de 2010. Para tanto, utilizamos os descritores "formação de professores", "formação docente", "inglês para crianças", "educação infantil" e "ensino fundamental I". A partir do título e do resumo dos artigos encontrados nessa busca, selecionamos aqueles que, de fato, tratavam de nossa temática de interesse e deparamo-nos com apenas três ${ }^{5}$ estudos publicados em dois periódicos distintos, conforme apresentado no Quadro 1, - que passaremos a comentar na sequência.

\footnotetext{
${ }^{5}$ É válido esclarecer que nas revistas classificadas como A1, encontramos um artigo publicado por Telma Gimenez, em coautoria com Jozélia Jane Corrente Tanaca, Rafaeli Constantino Valêncio Peres e Anísia Vieira de Oliveira, na revista Linguagem \& Ensino, no ano de 2013. Esse texto foi encontrado por meio do uso do descritor "inglês para crianças" e continha o termo em seu resumo. O objetivo do estudo é apresentar alguns dos desafios do projeto "Londrina Global", que promoveu a inserção da língua inglesa em escolas municipais. Embora o artigo apresente o item "Formação de professores em serviço", as autoras apenas descrevem como ocorriam os encontros dos docentes. Tendo em vista que o foco do artigo não foi analisar a formação de professores de LIC, e, por isso, esse tema foi brevemente mencionado, julgamos que esse estudo não faz parte do escopo deste levantamento, que visa discutir publicações sobre formação de professores de LIC. 
Quadro 1: Artigos sobre formação de professores de LIC publicados em revistas on-line A1 e A2 no período de 2010 a 2020.

\begin{tabular}{|c|c|c|c|c|}
\hline \multicolumn{5}{|c|}{ A1 } \\
\hline Periódico & Descritores & Título & Autor(es) & Publicação \\
\hline $\begin{array}{l}\text { Revista Bra- } \\
\text { sileira de } \\
\text { Linguística } \\
\text { Aplicada }\end{array}$ & $\begin{array}{l}\text { "Formação } \\
\text { docente" }\end{array}$ & $\begin{array}{l}\text { Professores de língua ingle- } \\
\text { sa para crianças: interface } \\
\text { entre formação inicial e } \\
\text { continuada, experiência e } \\
\text { fazer pedagógico. }\end{array}$ & $\begin{array}{l}\text { Leandra Ines } \\
\text { Seganfredo } \\
\text { Santos }\end{array}$ & $\begin{array}{l}2011, \\
\text { vol. } 11, \mathrm{n} . \\
\text { 1, pp. } 223- \\
246 .\end{array}$ \\
\hline \multicolumn{5}{|c|}{$\mathrm{A2}$} \\
\hline Calidoscópio & $\begin{array}{l}\text { "Formação } \\
\text { de } \\
\text { professores" }\end{array}$ & $\begin{array}{c}\text { O papel dos cursos de } \\
\text { Letras na formação de } \\
\text { professores de inglês para } \\
\text { crianças. }\end{array}$ & $\begin{array}{l}\text { Juliana Reichert } \\
\text { Assunção } \\
\text { Tonelli, Vera } \\
\text { Lúcia Lopes } \\
\text { Cristovão }\end{array}$ & $\begin{array}{c}2010, \\
\text { vol. } 8, \mathrm{n} .1 \\
\text { pp. } 65-76 .\end{array}$ \\
\hline Calidoscópio & $\begin{array}{l}\text { "Formação } \\
\text { docente" }\end{array}$ & $\begin{array}{c}\text { Formação docente e prática } \\
\text { pedagógica: o professor e o } \\
\text { aluno de língua estrangeira } \\
\text { em foco. }\end{array}$ & $\begin{array}{l}\text { Leandra Ines } \\
\text { Seganfredo } \\
\text { Santos }\end{array}$ & $\begin{array}{c}2010, \\
\text { vol. } 8, \text { n. } 1 \\
\text { pp. } 49-64 .\end{array}$ \\
\hline
\end{tabular}

Fonte: as autoras.

Conforme apresentado no Quando 1, nas revistas qualificadas como A1, encontramos um artigo de autoria de Leandra Ines Seganfredo Santos, publicado na Revista Brasileira de Linguística Aplicada, no ano de 2011. Intitulado "Professores de língua inglesa para crianças: interface entre formação inicial e continuada, experiência e fazer pedagógico", o artigo discute a formação inicial e continuada de professores de LIC do Ensino Fundamental I público. A pesquisa, de natureza qualitativa, foi realizada com cinco professoras da rede municipal de uma cidade do norte do Mato Grosso que participavam de um curso de formação continuada atrelado a um projeto de pesquisaextensão da Universidade do Estado do Mato Grosso. A análise dos dados, coletados por meio de instrumentos diversos, como questionários, entrevistas, sessões reflexivas, logs, acompanhamento do fazer pedagógico e da participação na formação continuada e em eventos acadêmico-científicos, mostrou a importância da formação continuada na vida profissional dos professores, em especial quando possibilitam a partilha de experiências. Importante ressaltar que a autora considera a formação docente como um processo de desenvolvimento profissional, sempre em construção, no qual a formação 
inicial e a formação continuada são indissociáveis, e que deve levar em consideração as experiências pessoais e profissionais dos professores.

Já nos periódicos classificados como A2, encontramos os artigos "O papel dos cursos de Letras na formação de professores de inglês para crianças", de Juliana Reichert Assunção Tonelli e Vera Lúcia Lopes Cristovão, e "Formação docente e prática pedagógica: o professor e o aluno de língua estrangeira em foco", de Leandra Ines Seganfredo Santos, ambos publicados no mesmo volume da revista Calidoscópio, no ano de 2010.

O estudo de Tonelli e Cristovão (2010) tem como objetivo (re)pensar aspectos do curso de Letras, visando preparar professores em formação inicial para atuarem no ensino de línguas estrangeiras para crianças. Para a realização da pesquisa, as autoras analisaram um questionário aplicado a 11 alunos da disciplina eletiva "Ensino de Língua Inglesa para Crianças" de um curso de Letras de uma universidade pública do norte do Paraná. As análises foram pautadas no interacionismo discursivo, considerando que "a produção de qualquer texto é necessariamente influenciada pela situação de produção" (TONELLI; CRISTOVÃO, 2010, p. 65) e mostram a preocupação dos graduandos em Letras com relação à necessidade de formação específica para ensinar LIC. As autoras defendem que a formação inicial nos cursos de licenciatura em Letras precisa ser mais abrangente para contemplar as demandas dos professores de inglês.

O objetivo do trabalho de Santos (2010, p. 49), por sua vez, é "apresentar e discutir o papel do professor e do aluno de língua estrangeira, especificamente, de ensino de língua estrangeira para crianças em contexto regular de ensino fundamental público". Para tanto, os dados foram obtidos das cinco professoras de LIC da rede municipal de uma cidade do norte do Mato Grosso, participantes de um curso de formação continuada atrelado a um projeto de pesquisa-extensão da Universidade do Estado do Mato Grosso, por meio de entrevistas, observação participante e registro em diário reflexivo. Baseando-se em teorias de formação para uma prática reflexiva, a autora categoriza as aulas observadas e as falas das participantes no que tange o papel do professor de língua estrangeira/língua estrangeira para crianças, que é apresentado como parte de perspectivas estruturantes ou interativo-construtivistas. É possível notar que as participantes apresentam ambas perspectivas em determinados momentos do processo de ensino-aprendizagem, mostrando também indícios para uma mudança para a perspectiva interativo-construtivista, de forma que Santos (2010, p. 49) conclui que "as docentes se encontram em momento de transição entre as perspectiva estruturante e interativoconstrutivista de formação". 
Em suma, levando em consideração os estudos publicados no período de 2010 a 2020, foram encontrados apenas três trabalhos sobre formação de professores de LIC nas 63 revistas on-line brasileiras qualificadas no estrato A do Qualis Periódicos. Esses artigos apresentam natureza qualitativa e tratam tanto da formação inicial quanto da formação continuada de professores de inglês para a Educação Infantil e anos iniciais do Ensino Fundamental. Assim, os dados dos estudos que compõem nossa amostra foram coletados com alunos de curso de licenciatura em Letras que cursam disciplina eletiva na área ou com professores da rede municipal que participam de processos de formação continuada. Os dados evidenciam a preocupação dos licenciandos com a ausência de formação para que possam ensinar LIC nos anos iniciais da educação básica, a importância de momentos de reflexão e partilha de experiências ao longo da formação docente, bem como da formação continuada para a vida profissional dos docentes.

Tendo em vista os aspectos abordados nesses estudos, nos próximos itens discutiremos a formação inicial, a formação continuada e a formação crítica e planejada de professores de LIC.

\section{FORMAÇÃO INICIAL DOS PROFESSORES DE LIC}

A não obrigatoriedade do ensino de línguas estrangeiras nos anos iniciais da educação básica (BRASIL, 1996) implica, dentre outras coisas, na ausência de diretrizes para a formação de profissionais que ensinam a língua inglesa antes do sexto ano do Ensino Fundamental. Entretanto, dada a importância do professor de língua estrangeira, independente do contexto no qual atua, ter uma boa competência linguística e conhecer as abordagens e as metodologias de ensino, pesquisadores já apontavam a necessidade do professor de LIC ser graduado em curso de Letras (SANTOS, 2009; SANTOS; BENEDETTI, 2009) antes mesmo da publicação da resolução no 7 (BRASIL, 2010)

A referida resolução oficializa o profissional licenciado em Letras como o responsável pela disciplina "língua estrangeira” nos anos iniciais do Ensino Fundamental, entretanto, sabemos que o currículo dos cursos de Letras, via de regra, não contempla discussões acerca do ensino de línguas estrangeiras na infância (CRISTOVÃO; GAMERO, 2009; PIRES, 2001, 2004; SANTOS, 2005, 2009, 2011; SANTOS; BENEDETTI, 2009), sendo que o contato ocasional dos licenciandos com esse contexto de atuação parece estar ocorrendo nas disciplinas de estágio supervisionado e prática de ensino (LIMA; MARGONARI, 2010; WOLFFOWITZ-SANCHEZ, 2009; TUTIDA, 2016), em disciplinas optativas (TONELLI; CRISTOVÃO, 2010) ou em cursos de extensão (SCHWEIKART, 2016). 
Dos artigos que compõem nossa amostra, o de Tonelli e Cristovão (2010) é o que trata, diretamente, da formação inicial dos professores de LIC. As autoras defendem que a formação desse profissional deve ser abordada no curso de Letras e elencam as dimensões que devem ser consideradas nesse processo de formação.

Considerando as dimensões acima elencadas, entendemos que o professor de LIC deva: dominar a língua a ser ensinada/aprendida; considerar os contextos em que atua para poder transformar sua prática docente; exercer sua profissão bem fundamentado em bases teóricas, sem desconsiderar que prática e teoria estão intimamente imbricadas; dominar métodos e abordagens que sejam coerentes com as necessidades dos educandos; agir de forma crítica e reflexiva nos contextos em que se encontra; entre outros aspectos. Entendendo que os cursos de Letras devam se adaptar às novas realidades e necessidades no desempenho do ensino de línguas é que defendemos a formação (inicial e continuada) de profissionais que possam também atuar em contextos de ensino de LIC. Nessa perspectiva, defendemos a formação global e plural do profissional de LIC e, para tal, acreditamos na necessidade da inserção de programas para a formação desse professor, reforçando a concepção defendida por Tonelli (2008a) e Cristovão e Gamero (2009). (TONELLI; CRISTOVÃO, 2010, p. 68)

A partir da análise dos dados coletados, Tonelli e Cristovão (2010) discutem que os participantes do estudo reconhecem a lacuna existente no curso de Letras, assim como a necessidade e relevância da formação inicial para o ensino de LIC, destacando a importância de cursarem a disciplina eletiva tendo em vista as contribuições da mesma para a formação acadêmica e profissional dos graduandos.

Estudos apontam que diante da ausência de formação específica para atuar nos anos iniciais da educação básica, os professores de LIC podem embasar suas práticas docentes em abordagens tradicionais de ensino (RAMPIM, 2010; LIMA, 2019), as quais pouco favorecem o desenvolvimento de uma atitude positiva das crianças frente à aprendizagem de uma nova língua. Isso porque, os docentes tendem a reproduzir em sala de aula a forma como foram ensinados, suas visões de língua, de ensino e de aprendizagem, ou, ainda, a planejar suas aulas com base em livros didáticos voltados para crianças que, muitas vezes, privilegiam a repetição e memorização de vocábulos de modo descontextualizado, revelando uma concepção estruturalista de linguagem e behaviorista de aprendizagem (LIMA, 2011). Além disso, não podemos desconsiderar que a aprendizagem de uma língua estrangeira com fins utilitaristas, voltada ao mercado de trabalho, também leva os professores a um ensino mais gramaticista. 
Em artigo que também compõe nossa amostra, Santos (2010) critica abordagens focadas em regras gramaticais e repetições descontextualizadas, pois podem desmotivar o aluno para continuar aprendendo a língua inglesa. A autora pondera que, com o passar dos anos, o foco que inicialmente incidia na ludicidade e no afeto, acaba sendo alterado para o ensino estrutural da língua e defende que o ensino da língua inglesa seja significativo “já no momento em que acontece e não somente na idade adulta” (SANTOS, 2010).

Para que isso ocorra, entendemos que é preciso investir na formação dos professores de LIC e sabemos que a formação inicial de professores em geral apresenta limitações (MAUÉS, 2003; MIZUKAMI, 2013) e, no caso da licenciatura em Letras, "não consegue suprir todas as áreas necessárias a um bom professor" (BASSO, 2008, p. 115). Entretanto, tendo em vista a expansão da oferta do ensino de LIC e o aumento da demanda por profissionais para esse contexto, entendemos que seja urgente regulamentar a oferta do ensino de língua estrangeira para crianças em nosso país e, consequentemente, a formação de docentes para atuarem nos anos iniciais da educação básica para, então, reformular os currículos dos cursos de licenciatura em Letras, incluindo disciplinas específicas, conforme já apontado por diversos autores (CRISTOVÃO; GAMERO, 2009; SANTOS, 2009; SANTOS; BENEDETTI, 2009; TONELLI; CRISTOVÃO, 2010; TUTIDA, 2016), mas também criar espaços para a discussão de problemas da prática e favorecer a formação de um profissional que analise e reflita sobre a própria prática.

Enquanto a formação de professores de LIC nos cursos de licenciatura em Letras não é regulamentada, professores que atuam ou pretendem atuar na Educação Infantil e no Ensino Fundamental I estão buscando propostas de formação continuada de naturezas diversas (BACARIN, 2013; RAMPIM, 2010). No item a seguir, abordaremos a formação continuada dos professores de LIC na perspectiva do desenvolvimento profissional docente.

\section{FORMAÇÃO CONTINUADA DE PROFESSORES DE LIC NA PERSPECTI- VA DO DESENVOLVIMENTO PROFISSIONAL DOCENTE}

Embora o artigo de Tonelli e Cristovão (2010) focalize a formação inicial, as autoras defendem, também, a formação continuada dos professores de LIC, temática discutida por vários autores da área (LEMES; 2014; MACIEL, 2014; MORETTI, 2014; PAULINO, 2016; PIATO, 2014; SANTOS, 2009; SHIMOURA, 2005; TUTIDA, 2016; WOLFFOWITZ-SANCHEZ, 2009) e foco dos trabalhos de Santos $(2010 ; 2011)$ que compõem nossa amostra. 
De acordo com Gatti e Barreto (2009), o termo formação continuada de professores abrange tanto cursos realizados após o término da formação inicial ou ingresso na profissão, quanto iniciativas menos formais, como as partilhas com outros professores. As autoras alertam para o fato de que, ao invés de possibilitarem aprofundamento ou ampliação de conhecimentos, muitos cursos de formação continuada de professores no Brasil apresentam caráter compensatório, limitando-se a suprir lacunas de uma formação inicial precária.

O termo formação continuada, assim como vários outros (aperfeiçoamento, formação em serviço, reciclagem, dentre outros) são comumente utilizados como sinônimos de desenvolvimento profissional, segundo Marcelo García (1999, 2009). No entanto, o autor considera o conceito de "desenvolvimento profissional" como o mais adequado para enfatizar o professor como um profissional do ensino, já que "desenvolvimento" sugere evolução e continuidade, superando a tradicional justaposição entre a formação inicial e continuada dos professores.

Oliveira-Formosinho (2009) explica que os conceitos de formação continuada e desenvolvimento profissional de professores apresentam preocupações e enfoques distintos. Enquanto a formação continuada tem como foco as instituições, agentes, modalidades e os aspectos organizacionais da formação, o desenvolvimento profissional docente preocupa-se com os processos, os conteúdos aprendidos, os contextos de aprendizagem e o impacto nas aprendizagens de alunos e professores. Entretanto, a autora reconhece que, atualmente, as propostas de formação continuada estão mais centradas na escola e nos professores, valorizando o saber da experiência e considerando que não é possível mudar o professor sem que mudanças concretas ocorram em seu local de trabalho, aproximando-se, dessa forma dos processos de desenvolvimento profissional.

Em suas pesquisas, Santos $(2010 ; 2011)$ compreende a formação continuada na perspectiva do desenvolvimento profissional e explica que

Tal processo veicula a ideia de um percurso profissional, cuja trajetória não é linear (FI + exercício da profissão + FC), mas evolutiva em um continuum de experiências marcadas por fatores diversos, como sociais, políticos, pessoais e familiares que atuam como influências facilitadoras ou dificultadoras do processo de aprendizagem da profissão. (SANTOS, 2011, pp. 225-226)

Santos (2010) ressalta as contribuições dos momentos de reflexão propiciados pela participação das professoras na pesquisa realizada. Observamos nesse estudo, e em demais que tratam de formação continuada, a importância de oportunidades para trocas, 
compartilhamento de experiências, leituras e discussões de textos teóricos e elaboração de material didático, conforme descreve a autora

\begin{abstract}
De acordo com as docentes, e eu compartilho da mesma opinião, os vários momentos de reflexão contribuíram para compreenderem melhor as ações e atividades que desenvolvem em sala, o que possibilitou reestruturação da prática docente, no que diz respeito às escolhas metodológicas, seleção de materiais didáticos, dentre outros aspectos. A socialização de materiais, dúvidas, angústias, leituras, estudos e experiências propiciaram maior colaboração entre elas, de modo que começaram a desenvolver uma prática coletiva e reflexiva, conforme pressupostos discutidos neste estudo (Vieira-Abrahão, 2004; Vieira-Abrahão et al., 2005; Pimenta e Ghedin, 2005; Gimenez et al., 2008). (SANTOS, 2010, p. 62)
\end{abstract}

A pesquisadora defende a formação continuada como parte inerente do fazer pedagógico, destacando o caráter "coletivo, colaborativo e participativo da formação" (SANTOS, 2011, p. 228). Ao discutir trabalhos publicados sobre formação de professores de língua estrangeira para crianças no período de 2003 a 2007, Santos (2011, p. 231) aponta que

[...] é indispensável FI [formação inicial] e FC [formação continuada] crítico-reflexivas que abarquem conhecimentos teórico-metodológicos e que os professores estejam abertos a mudanças, o que implica envolvimento com seus pares, de diferentes formas.

Notamos que, quase uma década após, tal ponderação ainda é válida, visto que carecemos de formação docente adequada, além de leis que regulamentem o ensino de LIC, conforme pontuado pela autora. Concordamos com Santos (2011) que a formação do professor de línguas estrangeiras para crianças está sempre em construção e, portanto, é necessário relacionar a formação inicial e continuada com as experiências pessoais e profissionais dos docentes. Nesse sentido, defendemos a relevância de pensarmos a formação de professores de LIC de forma crítica e planejada, como argumentado no próximo item.

\title{
FORMAÇÃO DE PROFESSORES DE LÍNGUA ESTRANGEIRA PARA CRIANÇAS: CRÍTICA E PLANEJADA
}

Nos três trabalhos que compõem nossa amostra, encontramos o foco na formação crítica de professores de LIC. Santos (2010) se apoia na concepção de Revista X, v. 16, n. 3, p. 643-663, 2021. 
formação do professor reflexivo com base em Zeichner (2003; 2008) e Imbernón (2005), defendendo um enfoque crítico da docência (GÓMEZ, 2000). No trabalho de 2011, a autora acrescenta à discussão sobre formação docente a necessidade do investimento na relação entre formação inicial e formação continuada. Tonelli e Cristovão (2010, p. 68) argumentam que o professor de LIC precisa "agir de forma crítica e reflexiva nos contextos em que se encontra", indicando que a formação desse profissional deve contribuir para que isso ocorra.

Assim, embora com referenciais distintos, notamos consenso nos três estudos para que a formação do professor de LIC seja reflexiva e crítica, afastando-se da concepção de treinamento de professores e da visão tecnicista da docência. Tonelli e Cristovão (2010, p. 68) enfatizam o papel dos cursos de Letras em abarcar a formação do professor de inglês para a Educação Infantil e para os primeiros anos do Ensino Fundamental, argumentando a favor da implementação de programas que foquem na formação "global e plural do profissional de LIC".

Considerando que a atuação de professores de inglês para crianças já é realidade no Brasil, Tonelli et al. (2017) defendem que os cursos de Letras precisam discutir a formação desses profissionais para contextos reais de atuação. Nas palavras dos autores:

(...) Defendemos a importância de (re)pensar a formação inicial de professores/as de LI a partir da(s) realidade(s) por eles/as vivenciada(s) com vistas a promover uma formação que considere, de fato, as situações concretas de atuação docente sem nos esquivarmos do compromisso com uma sociedade que, ainda, não desistiu da escola. (TONELLI et al., 2017, p. 126)

Concordamos com os autores sobre a necessidade de possibilitarmos uma formação que contemple os contextos de prática desses professores, para os quais, a Educação Infantil ou os primeiros anos do Ensino Fundamental têm representado campos de atuação durante ou após a formação inicial. Nesse sentido, Santos (2011) também defende que a formação inicial e continuada de professores seja revista a fim de abordar as necessidades trazidas pela sociedade atual.

Temos observado um aumento nos trabalhos sobre ensino-aprendizagem de LIC e formação docente, sobretudo diante da expansão das escolas bilíngues e escolas com programas bilíngues (português e inglês) por todo o território nacional. Estamos cientes de que esse crescimento das escolas bilíngues está diretamente relacionado com uma demanda neoliberal, o que precisa ser problematizado. A procura pelo ensino de inglês cada vez mais cedo e a falta de regulamentação desse ensino acabam contribuindo para 
a legitimação de discursos acríticos e perigosos, como apontam Garcia (2011) e Parma (2013). Tais discursos, divulgados sobretudo nas mídias de massa, focam na visão da língua inglesa como um produto e o ensino como um serviço, como nos alerta Fortes (2017). É nesse cenário que precisamos redimensionar a formação do professor de LIC, para que ele esteja ciente dos fatores que envolvem esse processo e seja capaz de fazer escolhas informadas, não sendo treinado para ensinar conforme prescrito por determinado método ou manual do professor.

Portanto, concordamos com Menezes de Souza (2019) que precisamos problematizar os tão aclamados modelos de formação, metodologias de ensino e compreensões estruturais de língua, linguagem, ensino e aprendizagem. Defendemos uma formação crítica de professores de língua inglesa para crianças, a qual questiona visões hegemônicas da língua inglesa e funções utilitárias dessa língua na infância (ROCHA, 2013), visando a educação linguística dos aprendizes por meio de práticas pedagógicas transdisciplinares e críticas, como sugere Ferraz (2018), possibilitando experiências transformadoras para aprendizes e docentes (LEMES, 2017).

A formação crítica de professores de LIC valoriza a educação linguística com crianças (MALTA, 2019), as quais são protagonistas nesse processo e têm suas afetividades e individualidades respeitadas, em uma educação que considera a infância como possibilidade de descobertas e desenvolvimentos, e não como uma etapa que visa a preparar essa criança para o mercado de trabalho, proposta criticada por Garcia (2011). Assim, formar professores de LIC críticos é possibilitar que façam escolhas de acordo com o seu contexto e que construam conhecimentos em conjunto com as crianças e com base em suas vivências, como sugerido por Pardo (2019).

Tonelli e Cristovão (2010, p. 73) nos lembram que há a necessidade de expansão das pesquisas em linguística aplicada sobre o tema, visto que os recentes estudos na área de LIC podem ser entendidos como uma "possível reação às necessidades educacionais dos pequenos aprendizes e dos profissionais que atuam ou irão atuar junto a esse público". Observamos que além das pesquisas reativas aos acontecimentos nessa área, a formação do professor de LIC também vem acontecendo dessa forma. Há algumas propostas, mas a maioria parte de iniciativas individuais de pesquisadores envolvidos com essa área que oferecem curso de extensão, disciplinas optativas, grupos de estudo, pesquisas, entre outros. No entanto, julgamos que a formação do professor de LIC precisa ser planejada, pois esse contexto de atuação já é realidade, como posto em vários trabalhos. Defendemos que os cursos de Letras revejam seus programas para que contemplem a formação crítica do professor de LIC, e que esses profissionais sejam menos dependentes 
dos tais modelos "globais" de ensino e possam agir em práticas locais diante do que está disponível, conforme proposto por Merlo e Kawachi-Furlan (2020).

\section{CONCLUSÕES}

Neste trabalho, fizemos um levantamento dos artigos sobre formação de professores de LIC publicados no período de 2010 a 2020 em revistas on-line qualificadas no estrato A do Qualis CAPES. Foram encontrados três estudos (SANTOS, 2010; TONELLI; CRISTOVÃO, 2010; SANTOS, 2011) sobre o tema, com foco na formação inicial, continuada e crítica dos docentes que atuam no ensino de inglês na Educação Infantil ou anos iniciais do Ensino Fundamental.

A análise dos três estudos encontrados nos permite compreender como a formação desses profissionais tem sido discutida na literatura acadêmica, bem como identificar questões que merecem atenção dos pesquisadores da área.

Considerando que a formação docente é um processo que ocorre ao longo da vida, a formação inicial, apesar de ser fundamental, não é suficiente para formar os professores que a sociedade atual demanda. Sendo assim, muitos professores buscam propostas de formação continuada. Essa procura tem sido intensificada nos últimos anos, haja vista que o ensino de inglês para crianças já é realidade no Brasil. Embora a atuação do professor de LIC ainda seja predominantemente na rede particular de ensino, esse campo de trabalho e a formação docente precisam ser investigados, sobretudo diante da perigosa ideia de que os treinamentos e métodos globais possam preencher a lacuna que existe na formação inicial desse profissional.

Os trabalhos analisados criticam a falta de formação específica para os professores de LIC nos cursos de licenciatura em Letras, comprovando, inclusive, o interesse dos graduandos por disciplinas que tratem do ensino de línguas estrangeiras nos anos iniciais da educação básica (TONELLI; CRISTOVÃO, 2010). A formação continuada é compreendida como integrante do processo de desenvolvimento profissional e privilegia momentos de reflexão e partilha de experiências (SANTOS, 2010; 2011). Além disso, as autoras defendem a formação crítica dos docentes, de forma que eles possam fazer escolhas conscientes para os contextos nos quais atuam.

As discussões apresentadas nesses trabalhos, que foram publicados há dez anos, são ainda atuais. Assim, ressaltamos a urgência de se regulamentar a oferta do ensino de línguas estrangeiras na Educação Infantil e anos iniciais do Ensino Fundamental, bem como a relevância de desenvolver estudos na área de formação de professores de LIC, para que seja possível discutir questões teórico-metodológicas, bem como fatores Revista X, v. 16, n. 3, p. 643-663, 2021. 
contextuais e locais, que podem contribuir para a formação crítica e planejada do professor de inglês para crianças.

\section{REFERÊNCIAS}

ASSIS, E.P. A formação de professores de inglês dos anos iniciais: um estudo sobre o projeto Early Bird. 2018. 245f. Dissertação (Mestrado em Educação) - Instituto de Biociências do Campus de Rio Claro, Universidade Estadual Paulista "Júlio de Mesquita Filho". Rio Claro, 2018.

BACARIN, M. C. Formação de professores de inglês para crianças: caminhos a percorrer. 2013. 54f. Monografia (Especialização em Ensino e Aprendizagem da Língua Inglesa) - Universidade Norte do Paraná, Londrina, 2013.

BASSO, E. A. Adolescentes e a aprendizagem de uma língua estrangeira: características, percepções e estratégias. In: ROCHA, C. H.; BASSO, E. A. (Orgs.). Ensinar e aprender língua estrangeira nas diferentes idades: reflexões para professores e formadores. São Carlos: Claraluz, 2008, p. 115-142.

BRASIL. Lei no 9.394, de 20 de dezembro de 1996. Estabelece as diretrizes e bases da educação nacional. Diário Oficial [da] República Federativa do Brasil. Brasília: 1996. Disponível em: <http://portal.mec.gov.br/seesp/arquivos/pdf/lei9394_ldbn1.pdf>

BRASIL. Ministério da Educação. Resolução n ${ }^{0}$ 7, de 14 de dezembro de 2010. Fixa Diretrizes Curriculares para o Ensino Fundamental de 9 (nove) anos. Brasília: MEC/ CNE, 2010. Disponível em: <http://portal.mec.gov.br/dmdocuments/rceb007_10.pdf>

CHAGURI, J. P.; TONELli, J. R. A. Políticas de ensino e aprendizagem de línguas estrangeiras para crianças no Brasil: (re)discutindo fundamentos. In: Revista Linhas, Florianópolis, v.20, n.42, p. 281-302, 2019. Disponível em: <http://www.revistas.udesc. br/index.php/linhas/article/view/1984723820422019281>. Acesso em 01 abr. 2020.

CRISTOVÃO, V. L. L.; GAMERO, R. (2009). Brincar aprendendo ou aprender brincando? In: Trabalhos em Linguística Aplicada, Campinas, v. 48, n. 2, p. 229-245, 2009. Disponível em: $<$ http://www.scielo.br/scielo.php?pid=S0103$18132009000200005 \&$ script $=$ sci_abstract\&tlng=pt $>$. Acesso em 30 abr. 2020.

FERRAZ, D. M. Os sentidos de "crítico" na educação linguística: problematizando práticas pedagógicas locais. In: FERRAZ, D. M.; KAWACHI-FURLAN, C.J. (Orgs.) Educação linguística em línguas estrangeiras. Campinas, SP. Editora Pontes, 2018, p. $43-72$. 
FORTES, L. O acontecimento do 'ensino bilíngue': representações da língua inglesa entre memórias e políticas. In: Recorte, v. 11, n. 1, p. 1-18, 2014. Disponível em: <http:// periodicos.unincor.br/index.php/recorte/article/view/1221>. Acesso em 20 mar. 2020.

FORTES, L. Sentidos de legitimação do ensino bilíngue português-inglês: efeitos do discurso institucional. In: Revista Eletrônica de Estudos Integrados em Discurso e Argumentação, n. 13, p. 104-120, 2017. Disponível em: < http://periodicos.uesc.br/index. php/eidea/article/view/1356>. Acesso em 20 mar. 2020.

GARCIA, B. Quanto mais cedo melhor (?): uma análise discursiva do ensino de inglês para crianças. 2011. 216 p. Dissertação (Mestrado em Letras) - Faculdade de Filosofia, Letras e Ciências Humanas da Universidade de São Paulo. São Paulo, 2011.

GATTI, B. A.; BARRETO, E. S. S. Professores do Brasil: impasses e desafios. Brasília: UNESCO, 2009.

GÓMEZ, A. I. P. A função e formação do professor/a no ensino para a compreensão: diferentes perspectivas. In: A.I.P. GÓMEZ; J.G. SACRISTÁN, Compreender e transformar o ensino. $4^{\mathrm{a}}$ ed., Porto Alegre, Artmed, 2000, p. 353-375.

IMBERNÓN, F. Formação docente e profissional: formar-se para a mudança e a incerteza. $5^{\mathrm{a}}$ ed., São Paulo, Cortez, 2005.

LEMES, F. M. M. Formação crítica docente: uma experiência com seis professoras de inglês de Educação Infantil e $1^{a}$ fase do Ensino Fundamental. 2014. 142f. Dissertação (Mestrado em Linguística, Letras e Artes) - Universidade Federal de Goiás, Goiânia, 2014.

LEMES, F. M. M. Formação Crítica Docente e seu Reflexo no Ensino Crítico de Inglês para Crianças: Experiências Transformadoras. In: TONELLI, J. R. A.; PÁDUA, L. S.; OLIVEIRA, T. R. R. Ensino e Formação de Professores de Línguas Estrangeiras para Crianças no Brasil. Paraná: Appris. 2017, p. 151-175.

LIMA, A. P. Análise de propostas de avaliação de rendimento em livros didáticos de inglês para o Ensino Fundamental I. Dissertação (Mestrado em Linguística Aplicada) Instituto de Estudos da Linguagem, Universidade Estadual de Campinas, Campinas, 2011.

LIMA, A. P. Desenvolvimento profissional de professores de inglês para crianças do Ensino Fundamental I: possibilidades para a formação e o trabalho docente. Tese (Doutorado em Educação) - Instituto de Biociências do Campus de Rio Claro, Universidade Estadual Paulista «Júlio de Mesquita Filho». Rio Claro, 2019. 
LIMA, A. P.; MARGONARI, D. M. A prática de ensino e a formação de professores de inglês para crianças. In: ROCHA, C. H.; TONELLI, J. R. A.; SILVA, K. A. (Orgs.). Língua Estrangeira para crianças: ensino-aprendizagem e formação docente Campinas: Pontes, 2010, v. 7, p. 187-202.

LIMA, A. P.; SOUZA NETO, S. O desenvolvimento profissional de professores de língua inglesa: o que nos revela o mapeamento das dissertações e teses?. In: ROCHA, C. H.; BASSO, E. A. Ensinar e aprender nas diferentes idades - Vol 2. (prelo).

MACIEL, B. S. A. Professores em (co)construção: expectativas e percepções de professores quanto a processos (colaborativos) para seu desenvolvimento. 2014. 198f. Dissertação (Mestrado em Linguística Aplicada) - Programa Interdisciplinar de PósGraduação em Linguística Aplicada da Faculdade de Letras da Universidade Federal do Rio de Janeiro, 2014.

MALTA, L. S. Além do que se vê: educação crítica e letramentos, formação de professores e prática docente no ensino de inglês para crianças de 2 a 5 anos. 2019. 127f. Dissertação (Mestrado em Linguística) - Universidade Federal do Espírito Santo, Vitória, 2019.

MARCELO GARCIA, C. Formação de professores: para uma mudança educativa. Porto: Porto Editora, 1999.

MARCELO GARCIA, Carlos. Desenvolvimento Profissional: passado e futuro. Sísifo - Revista das Ciências da Educação, n. 08, p. 7-22, 2009. Disponível em: < https://idus. us.es/xmlui/handle/11441/29247>. Acesso em 15 mar. 2020.

MAUÉS, O. As políticas de formação de professores: a "universitarização e a prática". In: Série Estudos - Periódico do Mestrado em Educação da UCDB. Campo Grande-MS, n. 16, p. 165-179, 2003.

MENEZES DE SOUZA, L. M. T. Educação linguística: repensando os conceitos de língua e linguagem. In: FERRAZ, D. M.; KAWACHI-FURLAN, C. J. Bate-papo com educadores linguísticos: letramentos, formação docente e criticidade. São Paulo: Pimenta Cultural, 2019, p. 245-258.

MERLO, M. C. R; KAWACHI-FURLAN, C.J. Língua e linguagem na educação de língua estrangeira para crianças: reflexões sobre filosofias da linguagem estruturalista e pósestruturalista. REVELLI - Revista de Educação, Língua e Literatura da UEG-Inhumas, v. 12, p. 1-19, 2020.

MIZUKAMI, M. G. N. Escola e desenvolvimento profissional da docência. In: GATTI, B. A. et al. (Orgs.). Por uma política nacional de formação de professores. São Paulo: Editora Unesp, 2013, p. 23-54. 
MORETTI, L. V. Os formadores e o desenvolvimento profissional de professores de inglês: diferentes olhares, diferentes práticas. 2014. 128 f. Dissertação (Mestrado em Educação) - Faculdade de Educação da Universidade de São Paulo, 2014.

OLIVEIRA-FORMOSINHO, J. Desenvolvimento profissional dos professores. In: FORMOSINHO, J. (Coord.). Formação de professores. Aprendizagem profissional e acção docente. Porto: Porto Editora, 2009, p. 221-284.

PARMA, A. F. Ensino infantil da língua inglesa no Brasil: uma análise discursiva da evidência do "quanto mais cedo melhor". 2013. 168 p. Dissertação (Mestrado em Linguística) - Universidade Estadual de Campinas, Instituto de Estudos da Linguagem, Campinas, 2013.

PARDO, F. S. O ensino de inglês nos anos iniciais da escola pública: por quê? Para quê? Para quem?. Em: PERcursos Linguísticos, Vitória (ES), v. 9, n. 23. Dossiê: Ensinoaprendizagem de línguas estrangeiras com crianças, p. 12-29, 2019.

PAULINO, E. S. Formação Continuada de professores de inglês da rede pública: uma proposta de produção de atividades baseadas em corpora. 2016.235f. Dissertação (Mestrado em Linguística Aplicada) - Programa de Pós-Graduação em Estudos Linguísticos da Faculdade de Letras da Universidade Federal de Minas Gerais, Belo Horizonte, 2016.

PIATO, G. C. Alinhamentos para uma formação adequada de professores de língua estrangeira para crianças (inglês). 2015. 103f. Dissertação (Mestrado em Linguística Aplicada) - Universidade de Brasília, Brasília, 2015.

PIRES, S. S. Vantagens e desvantagens do ensino de língua estrangeira na educação infantil: um estudo de caso. 2001, 131f. Dissertação (Mestrado em Estudos da Linguagem) - Instituto de Letras, Universidade Federal do Rio Grande do Sul, 2001.

PIRES, S. S. Ensino de inglês na Educação Infantil. In: SARMENTO, S.; MÜLLER, V. (Orgs.). O Ensino do Inglês como Língua Estrangeira: Estudos e Reflexões, Porto Alegre, 2004, p. 19-42.

RAMPIM, M. F. Relações entre a formação e a prática do professor de língua estrangeira (Inglês) para crianças. 2010. 117f. Dissertação (Mestrado em Linguística) - Programa de Pós-Graduação em Linguística da Universidade Federal de São Carlos, São Carlos, 2010.

ROCHA, C. H. Provisões para ensinar LE no ensino fundamental de $1^{a}$ a $4^{a}$ séries: dos parâmetros oficiais e objetivos dos agentes. 2006. 353p. Dissertação (Mestrado em Linguística Aplicada) - Instituto de Estudos da Linguagem, Universidade Estadual de Campinas, Campinas, 2006. 
ROCHA, C. H. O ensino de LE (inglês) para crianças do ensino fundamental público na transdisciplinaridade da linguística aplicada. In: TONELLI, J. R. A.; RAMOS, S. G. M (Orgs.). O ensino de LE para crianças: reflexões e contribuições. Londrina: Moriá, 2007, p. 1-34.

ROCHA, C. H. Práticas de letramento crítico, ensino plurilíngue e língua inglês em contexto acadêmico-universitário. Contexturas: ensino crítico de língua inglesa, São Paulo n. 20, p. 9-35, 2013.

ROMANOWSKI, J. P. ; ENS, R. T. As pesquisas denominadas do tipo "estado da arte" em educação. In: Diálogo educacional, v. 6, n. 19, p. 37-50, 2006. Disponível em: <https:// periodicos.pucpr.br/index.php/dialogoeducacional/article/view/24176>. Acesso em 03 mai. 2020.

SANTOS, L. I. S. Crenças acerca da inclusão de Língua Inglesa nas séries iniciais: Quanto antes melhor? 2005. 230f. Dissertação (Mestrado em Estudos de Linguagem) Instituto de Linguagens da Universidade Federal de Mato Grosso, Cuiabá, 2005.

SANTOS, L. I. S. Língua inglesa em anos iniciais do ensino fundamental: fazer pedagógico e formação docente. 2009. 274f. Tese (Doutorado em Estudos Linguísticos) - Instituto de Biociências, Letras e Ciências Exatas da Universidade Estadual Paulista - Campus de São José do Rio Preto, São José do Rio Preto, 2009.

SANTOS, L. I. S. Formação docente e prática pedagógica: o professor e o aluno de língua estrangeira em foco. In: Calidoscópio, v. 8, n. 1, p. 49-64, 2010. Disponível em: $<$ http://revistas.unisinos.br/index.php/calidoscopio/article/view/158/14>. Acesso em 02 fev. 2020.

SANTOS, L. I. S. Professores de língua inglesa para crianças: interface entre formação inicial e continuada, experiência e fazer pedagógico. In: Revista Brasileira de Linguística Aplicada, Belo Horizonte, v. 11, n.1, pp. 223-246, 2011. Disponível em: <http://www. scielo.br/pdf/rbla/v11n1/v11n1a12.pdf $>$. Acesso em 02 fev. 2020.

SANTOS, L. I. S.; BENEDETTI, A. M. Professores de língua estrangeira para crianças: conhecimentos teórico-metodológicos desejados. In: Trabalhos em Linguística Aplicada, Campinas, v. 48, n. 2, p. 333-351, 2009.

SCHWEIKART, J. F. A formação inicial do professor de línguas por meio do uso de recursos tecnológicos no ensino de língua inglesa para crianças: conflitos e contradições. 2016, 185f. Tese (Doutorado em Estudos Linguísticos) - Programa de Pós-Graduação em Estudos Linguísticos do Instituto de Biociências, Letras e Ciências Exatas da Universidade Estadual Paulista "Júlio de Mesquita Filho", Campus de São José do Rio Preto, São José do Rio Preto, 2016. 
SHIMOURA, A. S. Projeto de formação de professores de inglês para crianças: o trabalho do formador. 2005, 184pp. Tese (Doutorado em Linguística Aplicada e Estudos da Linguagem) - Pontifícia Universidade Católica de São Paulo, São Paulo, 2005.

TANACA, J. J. C. Aprendizagem expansiva em espaços híbridos de formação continuada de professoras de inglês para crianças no projeto Londrina Global. 2017. 255f. Tese (Doutorado em Estudos da Linguagem) - Universidade Estadual de Londrina, Londrina, 2017.

TONELLI, J. R. A; CRISTOVÃO, V. L. L. (2010). O papel dos cursos de Letras na formação de professores de inglês para crianças. In: Calidoscópio, v. 8, n. 1, p. 6576, 2010. Disponível em: <http://revistas.unisinos.br/index.php/calidoscopio/article/ view/159/15>. Acesso em 3 fev. 2020.

TONELLI, J. R. A. ; FERREIRA, O. H. S. ; BELO-CORDEIRO, A. E. Remendo novo em vestido velho: uma reflexão sobre os cursos de letras-inglês. In: Revista de Educação, Linguagem e Literatura, v. 9, n. 1 , p. 124-141, 2017. Disponível em: <https://www. revista.ueg.br/index.php/revelli/article/view/5666>. Acesso em 3 fev. 2020.

TONELLI, J. R. A.; PÁDUA, L. S. O estado da arte de pesquisas sobre ensino e formação de professores de línguas estrangeiras para crianças no Brasil. In: TONELLI, J. R. A.; PÁDUA, L. S.; OLIVEIRA, T. R. R. (Orgs.) Ensino e Formação de Professores de Línguas Estrangeiras para Crianças no Brasil. Curitiba: Appris, 2017, p.17-31.

TUTIDA, A. F. Ensino de língua inglesa para crianças: questões sobre formação de professores e os saberes da prática. 2016. 339f. Dissertação (Mestrado em Estudos de Linguagem) - Universidade Estadual de Londrina, 2016.

WOLFFOWITZ-SANCHEZ, N. Formação de professores para a educação infantil bilíngue. 2009. 217pp. Dissertação (Mestrado em Linguística Aplicada e Estudo Pontifícia Universidade Católica de São Paulo, São Paulo, 2009.

ZEICHNER, K. M. Formando professores reflexivos para a educação centrada no aluno: possibilidades e contribuições. In: R.L.L. BARBOSA (Org.), Formação de educadores: desafios e perspectivas. São Paulo, Editora UNESP, 2003, p. 35-55.

ZEICHNER, K. M. Uma análise crítica sobre a "reflexão" como conceito estruturante na formação docente. Educação \& Sociedade, v.29, n.103, p.535-554, 2008. 